\title{
AS PLATAFORMAS DE SOLUÇÃO DE LITÍGIOS ONLINE (ODR) E A SUA RELAÇÃO COM O DIREITO FUNDAMENTAL AO ACESSO À JUSTIÇA ${ }^{1}$
}

\section{ONLINE DISPUTE RESOLUTION (ODR) PLATFORMS AND THEIR RELATION TO THE FUNDAMENTAL RIGHT OF ACCESS TO JUSTICE}

\section{Mateus de Oliveira Fornasier} Doutor em Direito Público pela Universidade do Vale do Rio dos Sinos (UNISINOS). Professor do Programa de PósGraduação Stricto Sensu (Mestrado e Doutorado) em Direitos Humanos da Universidade Regional do Noroeste do Estado do Rio Grande do Sul (UNIJUÍ). Ijuí/RS. E-mail: mateus.fornasier@gmail.com

Matheus Antes Schwede Mestrando em Direitos Humanos da Universidade Regional do Noroeste do Estado do Rio Grande do Sul (UNIJUÍ). Ijuí/RS. E-mail: matheusschwede@gmail.com

RESUMO: Este artigo investiga como a utilização das plataformas de (ODR) pode oferecer agilidade, baixo custo e eficácia para a resolução de disputas, e como essas podem oferecer segurança jurídica para os seus usuários através de uma regulação necessária. Plataformas de ODR possibilitam mais celeridade na resolução de conflitos do que o processo judicial, em razão da essencialidade da tecnologia como meio, sendo que as partes se comunicam de forma assíncrona ou síncrona, mediante texto, áudio e vídeo, sendo possível a interatividade entre litigantes e conciliador, mediador ou árbitro. Seu método de procedimento hipotéticodedutivo, com abordagem qualitativa e técnica bibliográfica.

PALAVRAS-CHAVE: Resolução de disputas online; acesso à justiça; mediação; conciliação; arbitragem.

\footnotetext{
${ }^{1}$ Artigo recebido em 27/09/2020 e aprovado em 04/11/2020.
} 
ABSTRACT: This article investigates how the use of Online Dispute Resolution (ODR) platforms can offer agility, low cost and effectiveness for the resolution of disputes, and how they can offer legal safety to its users through necessary adjustment. ODR platforms enable faster resolution of conflicts than judicial process, due to the essentiality of technology as its means, with plaintiffs and defendants communicating asynchronously or synchronously, through text, audio and video, with the possibility of interactivity between litigants and conciliator, mediator or arbitrator. Its procedural method is hypothetical-deductive, with qualitative approach and bibliographic technique.

KEY WORDS: Online dispute resolution; access to justice; mediation; conciliation; arbitration.

\section{INTRODUÇÃO}

O começo do século XXI é marcado pela evolução e pela ubiquidade das tecnologias da informação e comunicação. Cotidianos e comportamentos vêm sofrendo diversas alterações em razão disso, não importando a localização e a cultura de cada sociedade. Aplicativos para os mais variados fins comerciais, de serviços, de produção e de entretenimento denotam que a tecnologia expande-se cada vez mais, invadindo todas as esferas de socialização no ambiente digital.

Ademais, já é de senso comum o fato de que atualmente se vive em um mundo globalizado - e, com tal globalização, torna-se possível o acesso imediato a inúmeras informações e formas de comunicação. A internet vem possibilitando a conectividade interpessoal instantânea, com poucos gestos e comandos de fácil domínio, não importando a distância entre os comunicantes. Tais comunicações possibilitam a aquisição de produtos e serviços, pelo cidadão comum, ainda que tal relação de consumo envolva pessoas em países diferentes em plataformas de vendas online. Essa possibilidade, porém, acarreta outra - a emergência de eventuais litígios consumeristas online.

Para realização do presente estudo, reconhece-se que não se pode mais imaginar o mundo sem a nova realidade trazida pela inovação das tecnologias da informação e 
comunicação. As TIC's se fazem presente em quase todas as ações humanas no século atual, trazendo novos paradigmas e consequentemente intensificando as relações pessoas. Por isso, é necessário analisar como os conflitos resultantes dessa interconexão podem ser solucionados rapidamente através da tecnologia, através do uso dos sistemas de Online Dispute Resolution (ODR, doravante).

Conforme vem ocorrendo essa significativa intensificação das relações humanas online, seja no comércio eletrônico ou em qualquer âmbito da vida, também começou a surgir um pensamento acerca de soluções eficazes, simples, rápidas e de baixo custo que pudessem solucionar os problemas litigiosos. Com isso, cerca de vinte anos atrás, em meados dos anos 1990 surgiu o primeiro exemplo de Online Dispute Resolution (ODR) — ou Resolução de Litígios Online, em português. Obviamente, com a intensificação das relações e os avanços tecnológicos, os sistemas de ODR começaram a tomar maior espaço, aparecendo com uma alternativa para resolução de conflitos. Muitos conflitos, como por exemplo no caso de consumidores no e-commerce, podem ser facilmente resolvidos através de plataformas online, como uma meio de resolução alternativa de litígios, só que sendo as ferramentas tecnológicas peças centrais para essa prática. Diante o sucesso dessas plataformas no âmbito do comércio online, outros âmbitos de conflitos voltaram seus olhares para o uso de ferramentas digitais, como nas áreas cível, trabalhista, e até criminal, nos casos de violência de gênero, mais especificamente. Dessa forma, os Tribunais vêm demonstrando grande interesse da implementação de softwares nos seus domínios, principalmente, devido à facilidade, o baixo custo e à celeridade — corroborando, assim, para mitigar a sobrecarga processual e para a devida promoção do direito ao acesso à justiça, bons motivos para a implementação e a utilização da tecnologia a favor das pessoas.

Por várias razões o estudo aqui proposto possui relevância para o contexto social do século XXI. Primeiramente, vale destacar que as tecnologias oferecem grande potencial para auxiliar a humanidade em diversas questões, quando devidamente regulamentadas e bem utilizadas. No ano de 2020, o qual foi assolado pela pandemia do COVID-19, impondo um isolamento social rígido, as TICs foram responsáveis por manter as pessoas conectadas e diversos trabalhos funcionando, bem como através dela que foi possível que os judiciários pudessem realizar algumas audiências e, novamente, expondo a capacidade das tecnologias serem bem utilizadas. Em segundo lugar, o acesso à justiça é um direito humano 
fundamental, o qual não se resume apenas ao direito de entrar com uma ação no judiciário, mas sim, à diversas situações como consulta jurídica, forma fácil e eficaz de resolver litígios, e etc. Isso significa que é um conceito bem amplo, onde as tecnologias podem desempenhar uma grande contribuição para esse direito.

O problema de pesquisa ora proposto pode ser expresso no seguinte questionamento: de que forma se pode correlacionar os mecanismos de ODR ao direito fundamental de acesso à justiça? Como hipótese, apresenta-se que as plataformas de ODR demonstram grande potencial para promover o acesso à justiça quando pensadas em todas as circunstâncias das sociedades e dos indivíduos. Dessa forma, o presente trabalho de pesquisa vai ao encontro dos estudos dos Direitos Humanos, do desenvolvimento e da democracia, visando construir um trabalho acerca das grandes possibilidades que a ODR pode trazer para a área jurídica.

Também é possível analisar que várias sociedades - e em especial, a brasileira têm aparentado ser extremamente litigiosas. Muitas vezes os Judiciários são movimentados por causas que poderiam ser facilmente resolvidas entre as partes, e por decorrência disso, acaba gerando uma sobrecarga nos tribunais, fazendo com que os processos andem a passos lentos para a sua resolução. De fato, algumas empresas privadas criaram plataformas para resolver as disputas com os clientes de uma forma mais simples e fácil, para evitar o encaminhamento do conflito ao judiciário. Já nos tribunais com a utilização de meios alternativos de litígios visaram reduzir essa grande quantidade de processos, e sendo incorporada os meios digitais à essas formas, oferecendo a possível conciliação entre as partes, também puderam oferecer agilidade e evitando a sobrecarga processual dos respectivos tribunais. Assim, reconhece-se também possibilidade da parceria públicoprivada para a criação da ODR, para o seu melhor desempenho.

Diante disso, este artigo, elaborado mediante o emprego do método de procedimento hipotético-dedutivo, com abordagem qualitativa e utilização da técnica de pesquisa bibliográfica, tem como objetivo geral investigar como a utilização das plataformas de (ODR) pode oferecer agilidade, baixo custo e eficácia para a resolução de disputas originadas tanto no meio digital como no âmbito físico, e como essas podem oferecer segurança jurídica para os seus usuários através de uma regulação necessária. Para a consecução de tal objetivo, dividiu-se o artigo em duas partes. A primeira delas estuda o que é a ODR, sua importância, qualidades, efeitos benéficos e problemas ainda persistentes para 
a sua completa implementação na busca da efetiva e rápida resolução dos conflitos que venham a surgir. Já a sua segunda parte tece explicações e correlações sobre a utilização dos meio digitais e o acesso à justiça, explicando que as plataformas devem ser acessíveis a todos, independentemente de quaisquer circunstâncias.

\section{Os sistemas de Resolução de Litígios Online}

Seria provavelmente inexplicável há 40 anos atrás convencer as pessoas de que elas poderiam resolver seus litígios e pendências dentro do conforto de sua casa, através de uma rede mundial de computadores cuja função é conectar todos da mesma forma e em um curto período de tempo. Hoje, é possível perceber que isso não se encontra mais no mundo das ideias, mas sim, no cotidiano. Dessa forma, é necessário destacar que os sistemas de ODR têm conquistado cada vez mais espaço devido à sua facilidade de utilização e acesso. Tendo isso em vista, é necessário entender como essas plataformas surgiram e como ocorrem as suas respectivas funcionalidades.

O conceito de ODR surgiu por volta do ano de 1996, quando o foco dessas plataformas se restringia unicamente à resolução de disputas originadas do âmbito da internet. Esses softwares facilitadores emergiram a partir do momento em que começou a se consolidar o entendimento de que as disputas que surgissem no meio digital não encontrariam muita dificuldade para sua solução em meio virtual. Vale destacar ainda que a utilização dos sistemas ODR, aproximadamente nos últimos vinte anos, vinha se concentrando quase que exclusivamente na solução de disputas originárias do comércio eletrônico. No entanto, passados alguns anos desde o início da sua utilização, e de forma recente, o potencial de uso dessas plataformas começou a ser melhor observado em relação a litígios que não são fossem especificamente de natureza patrimonial, nem mesmo que tivessem seu surgimento no mundo online. ${ }^{2}$

De fato, o avanço das tecnologias de informação e comunicação (TICs) possibilitou maior interação e consequentemente maior intensificação nas relações humanas, nos mais variados aspectos, ainda que essas relações ocorram em um ambiente totalmente digital.

\footnotetext{
2 ZELEZNIKOW, John. Can artificial intelligence and online dispute resolution enhance efficiency and effectiveness in courts. In: International Journal for Court Administration, v. 8, n. 2, p. 30-45, 2016. DOI: http://doi.org/10.18352/ijca.223.
} 
Algumas barreiras foram rompidas e novos paradigmas foram alcançados, mudando a forma de compreender a interatividade e a interconectividade. Com essas novas formas de vivência, o mundo digital propôs ao cidadão uma maior comodidade para realizar suas tarefas e seus desejos. A possibilidade de poder realizar compras no e-commerce sem sair de casa, com apenas alguns cliques, escolhendo produtos a partir de uma análise prévia em lojas online, que cediam as mais variadas especificações e uma quantidade inimaginável de bens para todos os gostos, fez com que o ser humano começasse a utilizar cada vez mais essas facilidades. Mas, como ocorre em muitas questões humanas complexas, ao mesmo tempo que a internet possibilitou um modo mais fácil de realizar compras, muitos conflitos destas se originaram, os quais foram gradativamente aumentando e assim necessitando de um modo fácil e ágil para que se pudesse resolver as disputas geradas.

Uma das primeiras aparições dos ODR se deu por iniciativa do Ebay, famoso website de varejo cuja sede se localiza nos EUA, que uniu esforços com outro website similar, o SquareTrade.com. Essa parceria teve por objetivo a criação de uma plataforma digital que configurasse um meio onde os conflitos gerados no e-commerce pudessem ser resolvidos virtualmente, num espaço digital específico para negociação entre fornecedores e consumidores. A criação dessa plataforma se deu em virtude da elevada e notável quantidade de reclamações que foram surgindo por parte dos consumidores, em razão de problemas que ocorreram em compras nos sites de e-commerce, intermediadores responsáveis entre as partes em conflito. Por isso foi necessário pensar em um meio onde ambas os envolvidos no desacordo fossem ouvidos com a finalidade para se alcançar uma resolução da disputa que ali se originou. ${ }^{3}$

Com o passar dos anos as plataformas de ODR sofreram algumas alterações, incorporando uma série de inovações tecnológicas. À medida que a tecnologia passa a apresentar novas funções e modalidades, abrem-se novas opções gerando novas oportunidades,. Assim, todos os sistemas desse tipo, independentemente da área a que se relacionem, tendem a se atualizar, a renovar e integrar novas ferramentas à sua disposição. Com isso, é possível dizer que os sistemas de ODR passaram por diferentes fases de transição ao longo dos últimos anos.

\footnotetext{
${ }^{3}$ NASCIMENTO JUNIOR, Vanderlei Freitas. A evolução dos métodos alternativos de resolução de conflitos em ambiente virtual: on line dispute resolution. Revista Eletrônica da Faculdade de Direito de Franca, v. 12, n. 1, p. 265-282, 2017. DOI: https://doi.org/10.21207/1983.4225.439.
} 
Quatro fases distintas caracterizam a evolução das plataformas de ODR: (I) Quando na década de noventa (entre os anos 1990-1996) os métodos para a solução de litígios através da utilização da tecnologia ainda estavam em testes; (II) De 1997 a 1998 os sistemas de ODR passam a serem desenvolvidos de um modo mais dinâmico e aberto, pois foi nesse período que começaram a ser integrados nas metodologias de alguns websites, que passaram a apresentar tal ferramenta como possibilidade de solução viável para os conflitos que viessem a surgir em razão de suas atividades; (III) De 1998 a 2001 deu-se um período de grande desenvolvimento econômico e tecnológico, e as empresas passaram a aderir e investir nos métodos online; (IV) O ano de 2001 marcou o início de uma nova fase, quando métodos de ODR passaram a ser introduzidos nas Cortes dos Judiciários e nas Administrações Públicas ao redor do mundo. ${ }^{4}$

Em relação às fases de implementação das ODRs no Brasil, tem-se que a Lei 13.105 de 16 de março de 2015, o Código de Processo Civil brasileiro, inaugura possibilidades de aderência à ODR, principalmente no que tange ao texto do seu art. $334, \S 7^{\circ}$, que refere que "a audiência de conciliação ou de mediação pode realizar-se por meio eletrônico, nos termos da lei". Ademais, a Lei n 13.140 , de mediação e autocomposição, também de 2015, institui no seu art. 46 que a "mediação poderá ser feita pela internet ou por outro meio de comunicação que permita a transação à distância, desde que as partes estejam de acordo". Nesta senda, no ano de 2020, assolado pela pandemia do COVID-19, que aumentou o distanciamento físico entre as pessoas em razão de necessidades sanitárias, a Lei no 13.994 alterou a Lei n 9.099/95 dos Juizados Especiais Cíveis e Criminais, trazendo a possibilidade da conciliação não presencial no âmbito dos JECs, alterando o art. 22 e parágrafos de tal lei. Mais especificamente, o $\S 2^{\circ}$ do referido artigo passou a considerar "cabível a conciliação não presencial conduzida pelo Juizado mediante o emprego dos recursos tecnológicos disponíveis de transmissão de sons e imagens em tempo real, devendo o resultado da tentativa de conciliação ser reduzido a escrito com os anexos pertinentes”. Diante disso, já se percebe a necessidade de haver certa regulação para resolver as disputas no espaço cibernético. É um campo que ainda necessita ser melhor analisado pelas legislações, dada a evolução tecnológica que a sociedade apresenta.

\footnotetext{
4 MANIA, Karolina. Online dispute resolution: The future of justice. International Comparative

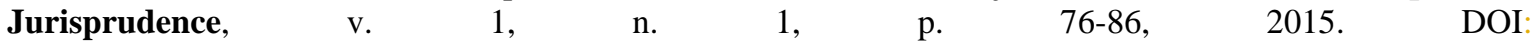
https://doi.org/10.1016/j.icj.2015.10.006.
} 
Plataformas de ODR podem auxiliar na resolução de milhares de disputas consumeristas, cujas partes estão localizadas em locais distantes e procurando modos fáceis e econômicos para resolvê-los. A mediação online, por exemplo é um fenômeno muito recente, mas que apresenta enorme potencial devido ao fato do aumento da interação dos cidadãos com a tecnologia. Na atualidade digitalizada, com mais acesso à internet de alta velocidade, e maior inclusão digital, a ODR representa grande facilitação, redução de dispêndio de recursos e encurtamento do tempo de duração dos conflitos, portanto. ${ }^{5}$ Mas quanto ao seu uso, ainda se fazem necessárias reformas funcionais e regulações para que sejam alcançados padrões uniformes de divulgação, bem como diretrizes de segurança, confidencialidade e autenticação dos procedimentos em todas as fases possíveis do processo — ou seja, ainda se deve objetivar um código padronizado para estabelecer a conduta dos mediadores online. Isso é extremamente importante para que certa transparência na utilização desses recursos tecnológicos seja obtida e mantida.

Vale ressaltar que inicialmente as plataformas de ODR foram criadas para solucionar os litígios consumeristas advindos do comércio eletrônico. Porém, com o passar do tempo foi-se percebendo sua eficácia, fácil acesso, baixo custo e gama de possibilidades inovadoras, e outras áreas passaram a dar mais atenção para as a ODR. Assim, tem-se que as ferramentas de ODR poderiam também ser de grande valia em casos de violência de gênero - principalmente no que tange à proteção da segurança da vítima devido ao perigo que procedimentos de tal natureza podem causar para a mesma, bem como em relação às possíveis manipulações do processo por intervenção do agressor. ${ }^{6}$ Essa modalidade de resolução pode ser útil principalmente naqueles casos que possa existir qualquer ameaça ou violência física, verbal ou psicológica do agressor à vítima. Aliás, para que essas plataformas desempenhem o seu devido funcionamento, elas devem ser projetadas de forma acessível, não apenas para as partes, mas como também para o terceiro neutro, o qual deverá

\footnotetext{
${ }^{5}$ PATIL, Ashok R. Role of Law Schools in Justice Delivery System through Online Mediation In: SANTANO, Ana Claudia; GABARDO, Emerson; NAGARATHNA, Annappa (org.). Direitos Fundamentais, Tecnologia e Educação. Curitiba: Íthala, 2019. p. 163-170. Disponível em: https://www.researchgate.net/profile/Sakshi_Goyal14/publication/342521131_Direitos_fundamentais_tecnol ogia_e_educacao_India/links/5ef97f1ca6fdcc4ca43a1f7c/Direitos-fundamentais-tecnologia-e-educacaoIndia.pdf\#page=164. Acesso em: 28 set 2020.

${ }^{6}$ MORALES, Emiliano Carretero. La utilidade de los ODR en los casos de violencia de género. Revista Eletrônica de Direito Processual, v. 18, n. 1, 2017. DOI: https://doi.org/10.12957/redp.2017.28490, p. 213214.
} 
previamente ter conhecimento do funcionamento da ferramenta que vai utilizar e também supervisionar se as partes envolvidas não apresentam qualquer problema ao utilizar a referida tecnologia. Além dessa melhor acessibilidade, as plataformas que serão utilizadas devem passar certa confiança e segurança para os envolvidos. Essas ferramentas já são usadas para lidar com questões familiares, quando as partes se encontram em diferentes localizações, ou algumas outras circunstâncias em que não era recomendado pessoas no mesmo espaço físico.

Levando-se em consideração a voluntariedade para o uso dessas ferramentas, é possível perceber alguns benefícios no uso de ODR nesse tipo de caso. Uma dessas vantagens seria que, através da utilização das plataformas de resolução de litígios online, os diversos programas de justiça restaurativa poderiam se apresentar mais facilmente acessíveis às vítimas, as quais por sua própria vontade procurariam este mecanismo, evitando a persistência da vítima em situação periclitante e com medo de encontrar seu agressor presencialmente. A implementação de justiça restaurativa por meios tecnológicos, portanto, possibilita certa facilidade para divulgá-la para que um maior número de pessoas tenha capacidade de acessá-la.

Aliás, é de grande valia acentuar o fato de que atualmente é perceptível que a ODR, com a evolução tecnológica, tem adotado as mais diversas ferramentas de utilização para facilitar que as partes envolvidas obtenham o melhor e mais rápido resultado para resolver seus litígios. Mas, não só isso, pois, ao mesmo tempo, as próprias plataformas, além de fazerem uma ponte facilitadora para comunicação entre as partes e um mediador, ao mesmo tempo têm apresentado capacidade de intervenção na resolução das disputas entre os litigantes com a utilização da inteligência artificial (IA).

Para explicar melhor o contexto referido acima, as ferramentas utilizadas nesse tipo de plataforma podem oferecer grande diversidade de formas de uso, as quais vão desde a negociação até a mediação, por meio de softwares criados com diferentes níveis de automação. De fato, há a existência de sistemas com a finalidade de negociação que não exigem qualquer tipo de intervenção humana e podem funcionar de forma automatizada, de forma que apenas as partes envolvidas na disputa participem. Esse modo funciona com 
propostas ou contrapropostas por intermédio do sistema de ODR. ${ }^{7}$ Porém, também é necessário levar em consideração que, quando se fala de aplicação de IA na ODR, é viável citar duas gerações distintas desta, sendo identificáveis em momentos: a) onde através da tecnologia se reconhece a necessidade da relação humana, como é o caso da utilização das mensagens de texto, e-mails, chats e videoconferências. Nessa geração ela se faz presente na disputa, por óbvio, mas sem qualquer autonomia no processo e; b) quando a tecnologia desempenha um papel decisório importante no processo. Aqui a intervenção humana é substituída por algoritmos que assumem a capacidade de resolução do conflitos. Considerase que esses sistemas são dotados de conhecimento e autonomia necessários para interpretar e emular as intenções humanas. ${ }^{8}$ Significa dizer que tal tecnologia oferece diversas formas de resolução de conflitos totalmente automatizados, por meio de uso de algoritmos, análise de dados e diversas formas de uso da IA. ${ }^{9}$

Uma solução interessante com o uso de IA e ODR pode ser proposta para o âmbito trabalhista, no qual há a forte tendência à realização de acordos. E nessa realidade, tem-se que o trabalhador muitas vezes se sente coagido a transacionar de forma prejudicial à sua situação, seja por pressão dos magistrados ou das necessidades que sua situação de desemprego lhe impende, numa cultura de celeridade acrítica caracterizadora de tais pressões. Assim, em razão de tais peculiaridades da seara trabalhista de conflitos, Paolinelli e Caspar ${ }^{10}$ sugerem que o uso de ferramentas de ODR no procedimento trabalhista pode vir a conferir maior equilíbrio e liberdade em favor do trabalhador, e menos intimidação em seu desfavor. Assim, sistemas que, automaticamente e com base em dados, analisem e comparem cada uma das propostas de acordo submetidas "às cegas" e, com base nos pontos em comum de tais minutas, elabore uma intermediária e dentro das margens do legalmente

\footnotetext{
${ }^{7}$ LIMA, Gabriela Vasconcelos; FEITOSA, Gustavo Raposo Pereira. Online dispute resolution (ODR): a solução de conflitos e as novas tecnologias. Revista do Direito, v. 3, n. 50, p. 53-70, 2016. DOI: http://dx.doi.org/10.17058/rdunisc.v3i50.8360.

8 AMORIM, Fernando Sérgio Tenório de. A resolução online de litígios (ODR) de baixa intensidade: perspectivas para a ordem jurídica brasileira. Pensar-Revista de Ciências Jurídicas, v. 22, n. 2, p. 514-539, 2017. DOI: https://doi.org/10.5020/2317-2150.2017.5397.

9 TAN, Vivi. Online dispute resolution for small civil claims in Victoria: A new paradigm in civil justice. Deakin Law Review, v. 24, p. 101, 2019. Disponível em: https://papers.ssrn.com/sol3/papers.cfm?abstract_id=3452952. Acesso em: 28 set 2020.

${ }^{10}$ PAOLINELLI, Camilla Mattos; CASPAR, Rafael Chiari. Reflexões sobre Direito, tecnologia e a utilização de ferramentas de Online Dispute Resolution em demandas trabalhistas In: ALVES, Isabella Fonseca (org.). Inteligência Artificial e Processo. Belo Horizonte: D’Plácido, 2020. p. 177-204; p. 200.
} 
possível, poderiam ser bastante adequados para a consecução dos direitos do obreiro litigante.

Mas é claro que, quando se trata da utilização de algoritmos e formas de IA judicial para funções decisórias, muita cautela é necessária. É perigoso confundir a realização da justiça com mera produtividade numérica — ou seja, se pode deixar enganar pela ideologia neoliberal no que tange à jurisdição. As resoluções dos litígios devem sim acontecer de modo correto conforme o Direito, e não meramente automática. Ainda que a tecnologia esteja bastante avançada, há uma grande quantidade problemas, como o viés algorítmico presença de preconceitos de gênero, de raça, de procedência nacional, etc., no modo de julgar, ou nos dados a partir dos quais a IA é treinada - e opacidade — impossibilidade de se identificar a lógica da máquina ao julgar, o que prejudica o contraditório, a ampla defesa, o devido processo legal e a recorribilidade das decisões. Significa dizer que programações tendenciosas e sem transparência podem interferir na efetivação de uma decisão justa entre as partes.

Quando essa temática é abordada, a questão que se refere ao uso desses sistemas automatizados para tomada de decisões, é que sistemas de IA interpretam dados e aprendem com eles. Em consequência disso, o potencial risco que se apresenta com essas tecnologias é que se em algum momento os dados que forem utilizados pelo sistema possuam qualquer viés preconceituoso, esse conteúdo será utilizado, transferido ou até mesmo amplificado no sistema de algoritmos. ${ }^{11}$ Em decorrência dessas situações é que se deve ter muito cuidado quanto ao uso das ferramentas de IA na tomada de decisões de caráter público, evitando que as minorias e os mais vulneráveis continuem sofrendo pelos preconceitos presentes na sociedade que possam ser amplificados pelas tecnologias.

Resta salientar que, levando as análises acerca das plataformas de resolução de litígios online, essas apresentam ferramentas com amplas utilidades e com muito potencial benéfico, principalmente pela criação de um ambiente interativo entre as partes, bem como a sua facilidade de acesso, seu baixo custo e a velocidade que os conflitos são resolvidos, o que acaba sendo muito atraente para o cidadão. A internet torna-se uma aliada daqueles que

\footnotetext{
${ }^{11}$ KAPLAN, Andreas; HAENLEIN, Michael. Rulers of the world, unite! The challenges and opportunities of artificial intelligence. Business Horizons, v. 63 , n. $1, \quad$ p. 37-50, 2020. DOI: https://doi.org/10.1016/j.bushor.2019.09.003.
} 
pretendem evitar esperar um longo tempo para uma conciliação de casos que na maioria das vezes se mostram ser simples e com a possibilidade ser facilmente resolvidos.

A tecnologia nos sistemas de resoluções de disputas pode desempenhar duas funções diferentes. Destaca-se, primeiramente, que é possível falar em uma forma onde os meios tecnológicos vem para auxiliar o sistema convencional de disputas já existente. Em segundo lugar, trata-se de um mecanismo online para resolução de disputas no meio digital. Pois é verdade que o ODR vem demonstrando desempenhar um ótimo papel na busca para a solução de conflitos que acabam por surgir entre empresas e consumidores. ${ }^{12}$ Ademais, a repercussão do sucesso oferecido pelos mecanismos de ODR fez com que uma grande quantidade de empresas começasse a promover a utilização dos sistemas de resolução de litígios online, através de negociação, mediação e arbitragem. $\mathrm{O}$ intuito no investimento dessas plataformas de ODR é, principalmente, evitar os longos processos. E, por causa disso, muitos consumidores também acabam por defender o uso das referidas plataformas, pelo simples fato de ser uma opção rápida, eficaz e que gera menos custos aos bolsos das partes envolvidas, principalmente do consumidor. ${ }^{13}$

Sistemas de ODR têm demonstrado grande flexibilidade, pois possibilitam a manutenção da comunicação de forma assíncrona — ou seja, permitem o compartilhamento de documentos, fotos, vídeos, áudio, ou seja, um amplo leque de possibilidades, onde não necessariamente todos precisam estar conectados ao mesmo tempo. Mas, não somente isso, esse tipo de plataforma pode abranger troca de mensagens de textos de forma simultânea, ou seja, síncrona, como também permitir chamadas de voz e vídeo para as mais diversas ocasiões, tornando a comunicação de fácil e simples proveito. Desse modo, as partes envolvidas na disputa e o terceiro neutro, por exemplo um mediador, não se encontram fisicamente no mesmo local, e também não necessariamente ao mesmo tempo. $\mathrm{O}$ mesmo ocorre com as testemunhas e os meios de provas utilizados. O processo de ODR deve ser iniciado online, bem como todos os outros procedimentos, até mesmo um acordo ou uma

\footnotetext{
${ }^{12}$ HASSAN, Kamal Halili et al. The use of technology in the transformation of business dispute resolution. European journal of law and economics, v. 42, n. 2, p. 369-381, 2016. DOI: https://doi.org/10.1007/s10657012-9375-7.

${ }^{13}$ GONZÁLEZ, Wendolyne Nava. Los mecanismos extrajudiciales de resolución de conflictos en línea: su problemática en el derecho internacional privado. ACDI-Anuario Colombiano de Derecho Internacional, n. 13, p. 5, 2020. DOI: http://dx.doi.org/10.12804/revistas.urosario.edu.co/acdi/a. 7524.
} 
decisão devem ser emitidos e distribuídos em formato digital e disponibilizado para os meios eletrônicos. Afinal, um processo de ODR é um processo virtual. ${ }^{14}$

Tendo em vista as inovações tecnológicas, muitos juristas começam a pensar em como será o futuro da advocacia, qual seria o papel específico dos advogados e demais tipos de procuradores no desempenho de suas funções. De fato, as transformações digitais alteram todo o cenário mundial, o que não deixaria de alterar como as profissões funcionam, se relacionam e se acabarão abrangendo novas funções. Por isso, é de grande valia analisar como a função do advogado irá se transformar com a utilização das plataformas de ODR, bem como quais os novos paradigmas que poderão ser alcançados.

$\mathrm{Na}$ verdade, mesmo que a representação possa diminuir em um sistema de ODR, ainda se verifica a necessidade dos advogados, pois estes fornecem conselhos jurídicos de forma eficiente e acessível. Nesse ambiente, os advogados desempenharão um papel determinante, aconselhando o cliente sem representá-lo no processo real. Os advogados na posição de conselheiros são necessário para analisar se o cliente tem uma reclamação, bem como os tipos de evidências mais vantajosos para obter determinado resultado. Ademais, os advogados também poderão aconselhar se é ou não mais vantajoso participar de um processo orientado para um acordo por meio do ODR, como por exemplo a mediação online, ao invés de ir pelo caminho dos processos judiciais. Outro tipo de função de aconselhamento pode ser o de optar ou não pela negociação nos bastidores ou conselhos de participação tática em todo o processo de ODR. Acredita-se que a capacidade dos advogados de preencher essa funções ditas deve informar o projeto dos sistemas de ODR, bem como contribuir para fortalecer os resultados justos que são visados. ${ }^{15}$ Ademais, diante da mudança de cenário na advocacia, espera-se que um sistema de ODR incentive os advogados a desenvolverem algumas habilidades, como a alfabetização digital, a facilitação da interdisciplinaridade, o amadurecimento de sua inteligência emocional, a confiança em habilidades cognitivas de nível superior e o empreendedorismo. Acredita-se que todas essas habilidades, se utilizadas em conjunto, poderão contribuir para um novo pensamento advocatício acerca da profissão

\footnotetext{
14 CALLIESS, Gralf-Peter; HEETKAMP, Simon Johannes. Online Dispute Resolution: Conceptual and Regulatory Framework. TLI Think, 2019. DOI: http://dx.doi.org/10.2139/ssrn.3505635.

15 EBNER, Noam; GREENBERG, Elayne E. Strengthening Online Dispute Resolution Justice. Washington University Journal of Law \& Policy, v. 63, n. 1, p. 065-118, 2020. Disponível em: https://openscholarship.wustl.edu/law_journal_law_policy/vol63/iss1/9/. Acesso em 28 set 2020.
} 
diante dos sistemas de ODR, com a finalidade de fortalecer a justiça e os serviços prestados pelos profissionais.

De fato, os efeitos globalizatórios exigem profundas alterações na sociedade, e a tecnologia não fica fora disso. Visando melhor alcançar e resolver os litígios, na ODR acabase por empregar novas funções em diversa áreas, não só nas de engenharia de software, mas também nas áreas das Ciências Sociais Aplicadas (Gestão, Direito, etc.), que é o âmbito em que essas ferramentas serão utilizadas, devendo transparecer segurança jurídica para os envolvidos e certo entendimento por parte daqueles que irão auxiliar alguém durante o uso dessas plataformas. Aliás, com essas novas habilidades, as habilidades cognitivas de ordem superior do advogado - analisar, sintetizar e avaliar situações, provas e argumentos, principalmente - terão relevância ainda maior no âmbito da ODR, que exigirá dos juristas compreensão cognitiva sobre uma gama mais ampla de assuntos do que apenas leis e estatutos, e um conhecimento interdisciplinar de como esses assuntos podem se cruzar no mundo real. O futuro de advogados na sociedade tecnológica dependerá de conhecimento e certa educação digital da sua parte, assim.

Ainda, além do conhecimento jurídico, os advogados deverão apresentar conhecimento de negócios sobre o setor do cliente e possui habilidades interpessoais, como a capacidade de empatia. Isso tudo ajudará os advogados a fornecerem o aconselhamento jurídico personalizado que os clientes buscam. Quanto mais especializações acerca da matéria da disputa, juntamente com conhecimento digital e do modo que se operam as plataformas ODR, mais capacitados serão os advogados e, consequentemente, os mais aptos a lidar com os novos desafios trazidos pela tecnologia. Além do mais, se reconhece a fantástica oportunidade das faculdades de direito ajustarem seus currículos para ensinar novas habilidades para os estudantes, diante a nova realidade digital. O uso das TICs está cada vez mais presente na realidade e cotidiano de todos. Conseguir uma educação digital desde a formação do profissional é de significativa importância, de modo que cada vez mais a sociedade caminha para melhor adaptação tecnológica.

Realmente existe uma expectativa de justiça que pode ser fornecida pelas plataformas de ODR: se os próprios usuários dessas considerarem as informações confiáveis, e que os conselhos e decisões alcançados nelas reflitam as expectativas dos usuários, os quais sejam adequadamente informados sobre os seus direitos, será possível um melhoramento 
significativo no acesso à justiça e na solução de disputas. ${ }^{16}$ É verdade que um código de ética também possa ser necessário para garantir a neutralidade de um software de ODR. Outra questão que deve ser pensada é sobre um padrão global de ODR, de forma que os usuários possam vir apresentar maior confiança nas plataformas e seus respectivos resultados. Desses modos, os desenvolvedores poderão ter mais clareza de que seus softwares estão fornecendo um serviço justo e os consumidores que utilizam do ODR para solucionar seus litígios de forma justa e barata. A confiança no sistema de resolução de disputas pela internet deve ser fundamental para a evolução do mesmo.

\section{A utilização de tecnologias nos Tribunais e o Acesso à Justiça}

Tendo em vista a crescente utilização de plataformas privadas de ODR, nas quais se verificou grande eficiência, essas ferramentas começaram a ser analisadas a partir de várias perspectivas, não mais somente no âmbito do Direito Privado e do Consumidor, passando a ser exploradas também pelos Tribunais ao redor do mundo. É muito comum ouvir críticas pela lentidão do andamento dos processos judiciais - então, como consequência disso, havendo alta litigiosidade principalmente no Brasil, o meio digital acabou aparentando ser uma solução interessantes.

Além das disputas do e-commerce, como já dito anteriormente, a tecnologia está sendo usada para lidar com litígios mais complexos, estando questões trabalhistas, de divórcio e disputas versando sobre quantias mais elevadas dentre as possibilidade de ser utilizado em várias outras áreas - e essa evolução decorrente da tecnologia, por mais que seja passível de muitas críticas e preocupações, pode expandir significativamente o acesso à justiça. Há poucos anos as pessoas acabavam não buscando a reparação por pequenos danos judicialmente pelo medo da demora do andamento de um processo e do desconforto que isso geraria. Porém, agora, os meios tecnológicos oferecem uma oportunidade de busca à reparação da melhor forma para as partes envolvidas, em um curto espaço de tempo. Deste modo, mais pessoas estão aderindo a essa prática. Parte dessa oportunidade de expandir o

\footnotetext{
${ }^{16}$ ABEDI, Fahimeh; ZELEZNIKOW, John; BELLUCCI, Emilia. Universal standards for the concept of trust in online dispute resolution systems in e-commerce disputes. International Journal of Law and Information Technology, v. 27, n. 3, p. 209-237, 2019. DOI: https://doi.org/10.1093/ijlit/eaz005.
} 
acesso à justiça já existe nos tribunais, mas essas novas opções também existem no sistema privado alternativo de resolução de conflitos. ${ }^{17}$

Assim, plataformas privadas, provedores de serviços jurídicos e tribunais notaram que poderiam aproveitar da internet como um todo para expandir de forma significativa o acesso à justiça para as pessoas em todos os níveis de renda e educação. Os softwares podem oferecer ajuda para as partes entenderem suas opções e para alcançar uma resolução justa para cada caso, de forma individual. ${ }^{18}$ No caso dos tribunais, após ver o sucesso que o ODR demonstrou em setores privados, como foi o caso da plataforma desenvolvida para o Ebay, tem-se que as Cortes reconheceram a necessidade de atualização em relação aos parâmetros atuais perante os anseios da sociedade.

Os tribunais eletrônicos (ou e-courts) são uma novidade no âmbito da resolução de conflitos. Funcionam no sistema judiciário convencional, mas suas operações se baseiam substancialmente em tecnologias que propiciam a virtualização nos mais variados sentidos em seus procedimentos — internet, computadores, câmeras, smartphones, etc. Mais especificamente, tais tribunais utilizam: a) arquivamento eletrônico, segundo o qual a documentação atinente aos casos são arquivados através de sistemas tecnológicos; b) gerenciamento de casos, mediante registros em um sistema digital; c) obtenções de evidências, através do uso de câmeras e transmissão/gravação de áudio; e d) videoconferência, ferramenta a qual permite, por exemplo, a produção de provas testemunhais e depoimentos em geral. ${ }^{19}$

Um claro exemplo de plataformas de ODR desenvolvidas e criadas não pela iniciativa de empresas privadas, mas sim no âmbito público, é a Plataforma Europeia para Resolução de Conflitos Online, criada pela Comissão Europeia, que começou suas atividades em 15 de fevereiro de 2016, tendo como principal objetivo oferecer aos consumidores e empresas na União Europeia a solução de conflitos relacionados ao $e$ -

\footnotetext{
${ }^{17}$ RULE, Colin. Online Dispute Resolution and the Future of Justice. Annual Review of Law and Social Science, v. 16, 2020. DOI: https://doi.org/10.1146/annurev-lawsocsci-101518-043049.

${ }^{18}$ RULE, Colin. Online Dispute Resolution and the Future of Justice. Annual Review of Law and Social Science, v. 16, 2020. DOI: https://doi.org/10.1146/annurev-lawsocsci-101518-043049.

${ }^{19}$ HASSAN, Kamal Halili et al. The use of technology in the transformation of business dispute resolution. European journal of law and economics, v. 42, n. 2, p. 369-381, 2016. DOI: https://doi.org/10.1007/s10657012-9375-7.
} 
commerce.$^{20} \mathrm{O}$ referido sistema nada mais é que um website interativo, gratuito e de fácil acesso, que funciona em todas as línguas oficiais do bloco europeu. Além disso, essa plataforma de ODR intermedia disputas entre consumidores e fornecedores, recebendo as reclamações das partes, oferecendo a possibilidade de resolver suas pendências de forma online, por meio de procedimentos extrajudiciais conduzidos pelas instituições de resolução alternativa de litígios de cada Estado-membro da União Europeia. ${ }^{21}$

Os sistemas de ODR chamam a atenção do Judiciário brasileiro porque, diante da grande litigiosidade do país e de sua sociedade, o sistema convencional acaba sendo sobrecarregado e, consequentemente, tornando a resolução das demandas lenta devido ao grande acúmulo de casos. Outro problema que se percebe é o alto custo que os trâmites legais acabam por gerar. Assim, dessa forma, a utilização de ODR em território brasileiro começa a aparecer como alternativa eficiente para a diminuição de demandas, abrindo espaço para uma forma alternativa de solução de conflitos, através da utilização da mediação online, principalmente.

A sociedade brasileira tem sido caracterizada por grande litigiosidade, seja pela ausência de um adensado Estado-providência, seja pela necessidade de se adquirir a "vitória" numa causa - mas paulatinamente essa realidade está aos poucos sendo revertida, cabendo aos juristas multiplicar os meios consensuais de resolução de conflitos. ${ }^{22}$ Para atender satisfatoriamente a demanda social por restauração da harmonia mediante a resolução de conflitos, não basta somente as mudanças legislativas, devendo um sistema multiportas emergir, com a introdução da mediação e da conciliação de forma intensa na processualística cível. Corrobora com esse entendimento o raciocínio de Vasconcelos e Carnaúba, ${ }^{23}$

\footnotetext{
${ }^{20}$ GONZÁLEZ, Wendolyne Nava. Los mecanismos extrajudiciales de resolución de conflictos en línea: su problemática en el derecho internacional privado. ACDI-Anuario Colombiano de Derecho Internacional, n. 13, p. 5, 2020. DOI: http://dx.doi.org/10.12804/revistas.urosario.edu.co/acdi/a. 7524.

${ }^{21}$ FUJITA, Maíra de Oliveira Lima Ruiz; ALMEIDA, Bianca Santos Cavalli. Meios de solução digital de conflitos-Online Dispute Resolution (ODR). Revista de Processo, Jurisdição e Efetividade da Justiça, v. 5, n. $2,2019 . \quad$ p. $19-35, \quad$ Disponível em: https://indexlaw.org/index.php/revistaprocessojurisdicao/article/view/5896. Acesso em: 28 set 2020.

${ }^{22}$ SILVA, Sabrina Jiukoski da; SILVA, Rafael Peteffi da; SANTOS, Ricardo Soares Stersi dos. A mediação e a conciliação como instrumentos de acesso à justiça e a sua perspectiva a partir do Código de Processo Civil: o contraponto entre a cultura da sentença e a cultura do consenso. Revista Eletrônica de Direito Processual, v. 21, n. 1, p. 392-415, 2020. DOI: https://doi.org/10.12957/redp.2020.44635.

${ }^{23}$ VASCONCELOS, Ronaldo; CARNAÚBA, César Augusto Martins. Custos de transação do processo e Online Dispute Resolution: um sistema multipartas 4.0 economicamente eficiente

In: LUCON, Paulo Henrique dos Santos et al. (coord.). Direito, Processo e Tecnologia. São Paulo: Thomson Reuters Brasil, 2020. p. 613-630.
} 
atualmente a resolução de conflitos deve ser entendida no contexto do sistema multiportas — ou seja, a partir do dever de fornecer ao litigante diversas alternativas aptas para se chegar a uma solução para a sua controvérsia. E nesse sentido, a ODR é extremamente relevante numa perspectiva econômica, pois contribui em grande medida para a redução dos custos de transação para as partes.

O Judiciário deve ser compreendido como a ultima ratio do sistema de Justiça, numa releitura do princípio do acesso à justiça. ${ }^{24}$ Assim, quando possível for o uso de mecanismos formais de recepção e justa apreciação, em tempo razoável, de reclamações, o requerimento administrativo para seu uso deve ser considerado como condição para o exercício do direito de ação perante o Judiciário. Por isso, a eficiência das ferramentas de ODR é uma questão de justiça social, para Becker e Feigelson ${ }^{25}$ - e, portanto, o condicionamento prévio do ajuizamento da ação à tentativa de composição do conflito extrajudicial funciona "como desarmador para a bomba-relógio que se tornou o Poder Judiciário do ponto de vista financeiro e de oportunidade para o erário e para a sociedade". Assim, embora parte da doutrina ortodoxa veja com maus olhos tal alternativa, a eventual negativa de solução extrajudicial anterior pode aumentar o rigor das punições aos réus, sendo criados, em razão da economia comportamental, incentivos para que os litigantes resolvam suas pendências autônoma, eficiente, rápida e justamente. Nesse mesmo sentido, Paro, Marques e Duarte ${ }^{26}$ apontam que a utilização de ODR no Judiciário brasileiro deve ser amplamente estimulada, em razão do melhor funcionamento deste em razão do aumento dos índices de solução extrajudicial do conflito. A via judicial deve ser considerada residual, limitada e excepcional, adstrita apenas a situações impossíveis de serem resolvidos pela via extrajudicial. Assim, pode-se combater a cultura da sentença, substituindo-a pela cultura da pacificação, uma transformação social necessária no que tange à solução de conflitos no Brasil. Porém, os meios proporcionados pela ODR devem, no contexto da justiça brasileira, ser tidos como

\footnotetext{
${ }^{24}$ GAJARDONI, Fernando da Fonseca. Levando o dever de estimular a auto-imposição a sério: uma proposta de releitura do princípio do acesso à justiça à luz do CPC/15. Revista Eletrônica de Direito Processual, v. 21, n. 2, p. 99-114, 2020. DOI: https://doi.org/10.12957/redp.2020.50802, p. 113.

${ }^{25}$ BECKER, Daniel; FEIGELSON, Bruno. Acesso à justiça para além de Cappelletti e Garth: a resolução de disputas na era digital e o papel dos métodos online de resolução de conflitos (ODR) na mitigação da crise de justiça no Brasil In: LUCON, Paulo Henrique dos Santos et al. (coord.). Direito, Processo e Tecnologia. São Paulo: Thomson Reuters Brasil, 2020. p. 205-220.

${ }^{26}$ PARO, Giácomo; MARQUES, Ricardo Dalmaso; DUARTE, Ricardo Quass. On-Line Dispute Resolution (ODR) e o interesse processual In: LUCON, Paulo Henrique dos Santos et al. (coord.). Direito, Processo e Tecnologia. São Paulo: Thomson Reuters Brasil, 2020. p. 277-326.
} 
formas de retirada de conflitos da jurisdição tradicional, a fim de que sejam direcionados a meios mais céleres, eficazes e baratos de solução ${ }^{27}$ - e não como algo generalizável em razão de um eficientismo acrítico.

Além do mais, a disparidade entre máquinas, isto é, o fato de um dos litigantes ter acesso a equipamentos melhores do que a outra, não representa um empecilho à utilização do ODR, pelo fato de que este não necessidade de uma grande capacidade de hardware, software, ou uma grande velocidade de internet para o pleno funcionamento da plataforma. Porém, é necessário levar em consideração que, no caso brasileiro, lidar com alguns dispositivos digitais e o acesso internet pode ser um problema, pois grande parte da população não possui qualquer tipo de acesso à internet. Todavia, é reconhecido o crescimento e a difusão da utilização da internet e demais meios digitais na sociedade. Outra situação evidenciável se encontra na falta de marcos legais específicos, embora isso não tenha impedido os avanços tecnológicos das experiências ODR no setor privado. Mas o problema mais relevante que se nota quanto ao assunto é relacionado ao setor público, onde há a existência de procedimentos mais rígidos e limitados no que tange aos litígios. De fato, há a possibilidade de que essas barreiras possam ser reduzidas com a implementação de políticas governamentais acerca do uso da ODR juntamente com os avanços proporcionados pela internet e demais formas de interação mediante o uso de TICs. ${ }^{28}$

De fato, as plataformas de ODR contribuíram muito com o acesso à justiça no mundo digital, pois, como já dito, os mecanismos oferecidos por esse tipo de software são mais rápidos e baratos quando comparados com os métodos tradicionais de resolução alternativa de litígios. ${ }^{29}$ Ademais, a promoção do acesso à justiça sob a ótica do direito brasileiro que o ODR apresenta é a garantia de um direito fundamental que está consagrado na Constituição Federal brasileira de 1988, em seu art. 5, XXXV, segundo o qual "a lei não excluirá da apreciação do Poder Judiciário lesão ou ameaça a direito". Ou seja, o uso do espaço

\footnotetext{
${ }^{27}$ PEREIRA, Luiz Fernando Casagrande; SCHINEMANN, Caio César Bueno. On-line Dispute Resolution no processo civil brasileiro: o caso das plataformas de indenização contra companhias aéreas In: LUCON, Paulo Henrique dos Santos et al. (coord.). Direito, Processo e Tecnologia. São Paulo: Thomson Reuters Brasil, 2020. p. 439-460.

${ }^{28}$ LIMA, Gabriela Vasconcelos; FEITOSA, Gustavo Raposo Pereira. Online dispute resolution (ODR): a solução de conflitos e as novas tecnologias. Revista do Direito, v. 3, n. 50, p. 53-70, 2016. DOI: http://dx.doi.org/10.17058/rdunisc.v3i50.8360.

${ }^{29}$ ANDERSON, Dorcas Quek. Ethical concerns in court-connected online dispute resolution. International Journal of Online Dispute Resolution, v. 5, n. 1-2, p. 20, 2019. DOI: https://doi.org/10.5553/IJODR/235250022018005102004.
} 
cibernético ao alcance da sociedade demonstra que está aberta uma gama de oportunidades para ser um meio facilitador para garantir os direitos postulados.

Porém, o acesso à justiça na realidade acaba muitas vezes não garantindo as decisões dentro do tempo relativamente adequado, extrapolando os prazos que atendam as necessidades de uma sociedade que visa soluções de seus conflitos e, não só isso, que também se acostumou a buscá-las no Judiciário. ${ }^{30}$ Atualmente, o número de processos que se encontram ativos no Judiciário brasileiro é extremamente grande para a sua estrutura e, por isso, é necessário reduzir a massiva quantidade de processos que chegam aos tribunais, onde, mais uma vez, os sistemas de ODR demonstram grande capacidade.

Tendo como objeto de análise o referido direito fundamental em relação ao notável avanço tecnológico, percebe-se a possibilidade de dizer que os meios de resolução de disputas no âmbito online aparecem como uma forma eficaz à solução de litígios, com a finalidade de alcançar a justiça social. ${ }^{31}$ Dessa forma, destaca-se que, a partir de determinados movimentos do processo civil, surgiu a intenção de buscar um melhor alcance, num âmbito externo, fora do Judiciário, o qual poderia ser visado pela utilização das resoluções alternativas dos litígios, considerando todos os avanços tecnológicos atuais, de modo que as plataformas de ODR poderiam oferecer uma melhor prestação jurisdicional. ${ }^{32}$

No entanto, verifica-se que mesmo o ODR se apresentando como uma nova forma de resolver os litígios, é devidamente necessário realçar o fato de que existem obstáculos para a sua plena eficácia no caso brasileiro, haja visto que grande parte da população não possui acesso à internet, ou a outros meios digitais. Desta forma, resta salientar que alguns passos devem ser tomados para a efetivação das resoluções de litígios online, principalmente pelo Poder Público, que venha a agir de melhor forma a garantir o acesso à justiça de uma maneira efetiva, respeitando a Carta Magna de $1988 .{ }^{33}$ A necessidade da existência de um

\footnotetext{
${ }^{30}$ SCHMIDT-KESSEN, Maria José; NOGUEIRA, Rafaela; GAMITO, M. Cantero. Success or Failure?Effectiveness of Consumer ODR Platforms in Brazil and in the EU. Journal of Consumer Policy, p. 1-28, 2020. DOI: https://doi.org/10.1007/s10603-020-09448-y.

${ }^{31}$ FUJITA, Maíra de Oliveira Lima Ruiz; ALMEIDA, Bianca Santos Cavalli. Meios de solução digital de conflitos-Online Dispute Resolution (ODR). Revista de Processo, Jurisdição e Efetividade da Justiça, v. 5, n. $2,2019.2$ p. $2019-35, \quad$ Disponível https://indexlaw.org/index.php/revistaprocessojurisdicao/article/view/5896. Acesso em: 28 set 2020.

32 OSNA, Gustavo. Acceso a la justicia, cultura y online dispute resolution. Derecho PUCP, n. 83, p. 9-27, 2019. DOI: http://dx.doi.org/10.18800/derechopucp.201902.001.

${ }^{33}$ FUJITA, Maíra de Oliveira Lima Ruiz; ALMEIDA, Bianca Santos Cavalli. Meios de solução digital de conflitos-Online Dispute Resolution (ODR). Revista de Processo, Jurisdição e Efetividade da Justiça, v. 5,
} 
quadro jurídico que venha a regular essas plataformas é realmente uma questão chave para que haja o desenvolvimento dos ODR no Brasil. Pois uma legislação adequada demonstra capacidade de facilitar a confiança nas atividades eletrônicas, porém, preservando a reparação judicial tradicional. Mesmo que a disputa venha a surgir no e-commerce, a estrutura das plataformas não deve anular o direito do consumidor de buscar qualquer reparação judicial. As ferramentas de comunicação oferecidas são capazes de proporcionar solução de lides em uma sociedade digital, ainda mais em razão da grande interconectividade atual. ${ }^{34}$

Aliás, devido ao período de pandemia global em que a população se encontra em 2020, tem-se percebido a grande dependência geral dos sistemas tecnológicos, os quais, por muitas vezes, facilitam a vida e ampliam o contato mesmo que à distância, respeitando as regras de isolamento social. Devido às medidas sanitárias urgentes atinentes ao combate ao novo coronavírus, muitas atividades tiveram que se adequar à nova realidade: regimes de home office nas mais variadas atividades, ensino online, audiências virtuais no Judiciário e funcionamento do Legislativo representam algo muito inovador e extremamente relevante em tais tempos.

De fato, o momento pandêmico do novo coronavírus tem mostrado alternativas para a condução das mais variadas atividades. Até mesmo a mediação e a arbitragem podem continuar sendo realizadas de forma virtual. Diante o fato do COVID-19, muitas instituições arbitrais responderam de forma rápida, com o intuito de se manter ativas, adequando seus métodos. Alguns tribunais e outras instituições já oferecem interações virtuais estipuladas em suas regras, bem como se demonstram preparadas e devidamente equipadas para manter as interações no âmbito digital. Já nos casos das instituições que demonstram não estar totalmente preparadas para a utilização do âmbito virtual como uma ferramenta necessária, muito provavelmente já estejam procurando fazer alterações, principalmente pela situação de isolamento social que a pandemia impôs. ${ }^{35}$

\footnotetext{
n. $2, \quad$ p. $2019 . \quad$ Disponível 25 em: https://indexlaw.org/index.php/revistaprocessojurisdicao/article/view/5896. Acesso em: 28 set 2020.

${ }^{34}$ ZANFERDINI, Flávia Almeidai Montingelli; OLIVEIRA, Rafael Tomaz. Online Dispute Resolution in Brazil: are we ready for this cultural turn? Revista Paradigma, v. 24, n. 1, 2015. Disponível em: http://revistas.unaerp.br/index.php/paradigma/article/view/589. Acesso em: 28 set 2020.

${ }^{35}$ SHOPE, Mark. The International Arbitral Institution Response to COVID-19 and Opportunities for Online Dispute Resolution. Contemporary Asia Arbitration Journal, 2020. Disponível em: https://papers.ssrn.com/sol3/papers.cfm?abstract_id=3616612. Acesso em: 28 set 2020.
} 
A situação pandêmica que assolou o mundo revelou que, no caso brasileiro, alguns tribunais não estavam preparados para sua disseminação. Ademais, entre alguns dos impactos gerados, é perceptível o cancelamento e a redesignação de audiências de conciliação e mediação, tendo em vista que não muitos dos tribunais optaram pela realização virtual das audiências. Porém, é possível notar o esforço que alguns têm realizado visando buscar novas técnicas diante a crise. Prova disso é a forma que os Tribunais de Justiça de alguns estados, como o Paraná, autorizaram a realização de sessões virtuais, por meio de aplicativos tecnológicos que foram responsáveis para manter pleno contato, como o WhatsApp, e-mail, chats e fóruns de conciliação virtual, da maneira que veio a facilitar o acesso à justiça, para as partes, as quais foram questionadas se demonstravam interesse em realizar as audiências dessa forma. ${ }^{36}$ Hoje existem inúmeros aplicativos com capacidade de criar pontes de comunicação entre as pessoas. Muitos passam conectados a maior parte do seu dia. Por isso, se vê a necessidade da criação de um sistema interativo, transparente, seguro e de simples manuseio, onde as pessoas poderiam iniciar as formas alternativas para solucionar suas demandas digitalmente, com alta velocidade se conclusão.

Todavia, reconhece-se a verdade de que a implementação de ODR no Brasil apresenta alguns empecilhos, ainda mais quando se analisa um país que possui uma enorme taxa de desigualdade social, em vários aspectos, entre eles, o uso da internet, além do fato de uma grande parte da população viver em zona rural. Por isso, resta dizer que no território brasileiro, o movimento para implementar essa nova forma de solução de conflitos é gradativa, necessitando ainda de uma maior e mais concentrada atuação do Poder Público para permitir uma melhor acessibilidade dos cidadãos à internet. ${ }^{37}$ Mesmo que gradativa, a implementação da tecnologia tanto no setor público como no privado demonstrou grande importância, ainda mais pelo momento atual que intensificou para o uso das TICs em absolutamente todos os aspectos da vida comunitária.

36 NETTO, José Laurindo de Souza; FOGAÇA, Anderson Ricardo; GARCEL, Adriane. Métodos autocompositivos e as novas tecnologias em tempos de COVID-19: online dispute resolution - ODR. Relações Internacionais no Mundo Atual, v. 1, n. 26, p. 21-32, 2020. DOI: http://dx.doi.org/10.21902/Revrima.v2i27.3989.

37 NETTO, José Laurindo de Souza; FOGAÇA, Anderson Ricardo; GARCEL, Adriane. Métodos autocompositivos e as novas tecnologias em tempos de COVID-19: online dispute resolution - ODR. Relações Internacionais no Mundo Atual, v. 1, n. 26, p. 21-32, 2020 . DOI: http://dx.doi.org/10.21902/Revrima.v2i27.3989. 
Outro fato é que a pandemia resultante do COVID-19, da qual resultou um rígido e necessário isolamento social, o Judiciário deve procurar meios de continuar concedendo o efetivo acesso à justiça à todos os cidadãos. A situação atual no mundo serviu como exemplo para que se veja a necessidade da Justiça continuar operando e entregando a prestação jurisdicional, adequando-se às novas realidades, ao novo momento em que se vive, principalmente no que tange ao ambiente digital. Diante disso, se vê que a realização de audiências online é a melhor saída para dar acesso à justiça em meio ao isolamento social, de forma que venha a garantir uma efetiva prestação jurisdicional que visa a justiça social. ${ }^{38}$

E quando se trata do acesso à justiça, deve-se pensar em todos os aspectos que esse direito engloba, pois não basta apenas criar uma plataforma de ODR - ela tem de ser plenamente acessível a todos, perante todos os tipos de adversidades que possam existir. $\mathrm{O}$ acesso à justiça é muito amplo, e nenhuma pessoa deve ser tolhida do seu direito fundamental, não importando a sua condição. Isso explica a urgência em se falar sobre a acessibilidade digital para a solução dos conflitos. Pois, de fato, como Nolan-Haley ${ }^{39}$ explica, o acesso à justiça tem uma gama de significados bastante ampla, podendo se referir, como por exemplo, à justiça ambiental, social, ou comercial, como também o direito ao acesso aos tribunais, à informação e até mesmo a um advogado.

Partindo deste ponto, na medida em que se apressa a procura de projetar e implementar os sistemas de ODR, é fundamental que se faça da promoção da acessibilidade digital uma prioridade, já que as pessoas com deficiência, por exemplo, nem sempre foram capazes de acessar de forma efetivas alguns sites da internet, principalmente antes do COVID. Mas, com as mudanças na sociedade e no âmbito tecnológico que a pandemia impôs, é importante se pensar nas reformas onde as deficiências não sejam excludentes nesses aspectos. $\mathrm{O}$ acesso às disputas é algo que deve ser essencialmente acessível a todas as pessoas. Pessoas com qualquer tipo de deficiência, desde temporárias à aquelas de limitações situacionais, como sensibilidade à luz ou ruídos, indivíduos com internet lenta ou

38 NETTO, José Laurindo de Souza; FOGAÇA, Anderson Ricardo; GARCEL, Adriane. Métodos autocompositivos e as novas tecnologias em tempos de COVID-19: online dispute resolution - ODR. Relações Internacionais no Mundo Atual, v. 1, n. 26, p. 21-32, 2020 . DOI: http://dx.doi.org/10.21902/Revrima.v2i27.3989.

${ }^{39}$ NOLAN-HALEY, Jacqueline. International Dispute Resolution and Access to Justice: Comparative Law Perspectives. Journal of Dispute Resolution, p. 391, 2020. Disponível em: https://scholarship.law.missouri.edu/cgi/viewcontent.cgi?article=1869\&context=jdr. Acesso em: 28 set 2020. 
limitada, podem se beneficiar de um design acessível. O conteúdo de vídeo ou legenda também pode beneficiar qualquer pessoa. De fato, uma plataforma bem projetada, com fácil forma de utilização também poderia beneficiar os mais idosos que geralmente apresentam alguma dificuldade. O conteúdo que é desenvolvido de forma universal, pode beneficiar a todos, tornando alcançável a acessibilidade digital. Deve-se considerar que sites, aplicativos, plataformas de softwares e quaisquer outras tecnologias somente serão acessíveis quando desenvolvidas e projetadas atendendo padrões de acessibilidade reconhecidos internacionalmente. ${ }^{40}$

Destaque-se que, para se alcançar uma acessibilidade digital em todos os sites, é necessário regulamentação e cooperação de milhares de pessoas. ${ }^{41}$ Pois somente com um esforço consciente é que se alcançará um ambiente online convidativo e mais compreensível para todos os seus usuários, independentemente se possuidores de qualquer limitação.

As adaptações exigidas pela pandemia aceleraram a transição de várias atividades para o âmbito online. A comunicação virtual está sendo o único meio de contato com o mundo exterior para aqueles que estão isolados. E, a partir disso, é necessário agir para garantir que as pessoas portadores de deficiência e outras populações vulneráveis não sejam excluídas. Os provedores de ODR devem ver a acessibilidade digital não como um mero ponto em sua lista, mas como um ponto crucial na projeção do sistema de ODR. ${ }^{42}$ Pois, afinal, é disso que se trata o acesso à justiça: possibilitar os meios para todas as pessoas buscarem a proteção dos direitos de que são titulares, suas necessárias reparações, não importando a condição em que se encontram.

\section{CONSIDERAÇÕES FINAIS}

\footnotetext{
${ }^{40}$ LARSON, David Allen. ODR Accessibility for Persons with Disabilities: We Must Do Better. Online Dispute Resolution: Theory and Practice (2nd ed. Eleven International Publishers, Forthcoming Fall 2020), 2020. DOI:http://dx.doi.org/10.2139/ssrn.3614838.

${ }^{41}$ LARSON, David Allen. ODR Accessibility for Persons with Disabilities: We Must Do Better. Online Dispute Resolution: Theory and Practice (2nd ed. Eleven International Publishers, Forthcoming Fall 2020), 2020. DOI:http://dx.doi.org/10.2139/ssrn.3614838.

${ }^{42}$ LARSON, David Allen. ODR Accessibility for Persons with Disabilities: We Must Do Better. Online Dispute Resolution: Theory and Practice (2nd ed. Eleven International Publishers, Forthcoming Fall 2020), 2020. DOI:http://dx.doi.org/10.2139/ssrn.3614838.
} 
Entende-se a partir desse estudo que, conforme a intensificação das relações humanas, dado o grande avanço tecnológico, no que tange à informação e à comunicação, uma nova game de possibilidades começa a surgir no âmbito dos procedimentos para a resolução de conflitos. Para resolver os litígios que originalmente surgiam no âmbito do consumidor, mais especificamente no e-commerce, surgiram as plataformas de ODR, as quais, por demonstrarem facilidade de utilização e acesso, começaram a chamar atenção não só do setor privado, mas também do público, nos Judiciários ao redor do mundo. E, a partir disso, a ODR passou a ser usada também em outros tipos de conflitos, tais como trabalhistas, de família, em casos de violência de gênero, etc. - principalmente por causa da facilidade, da segurança e dos demais benefícios proporcionados às partes envolvidas. Aliás, também é necessário que hoje o mundo se mostre completamente às tecnologias e, por isso, essas ferramentas tendem a expandir grandes possibilidades, principalmente para as pequenas causas e uma melhor efetivação do direito fundamental do acesso à justiça.

As plataformas de ODR possibilitaram o aumento da celeridade na resolução dos conflitos, os quais pela via tradicional levaria um maior tempo para ser resolvido. Destacase também que a tecnologia, nessa forma de resolução de litígios, funciona como peça essencial, pois através dos seus meios as partes poderão se comunicar de forma assíncrona ou síncrona, pela utilização de chats de texto, de voz, ou de vídeo, bem como o envio de documentos, dentre inúmeras formas de compartilhamento de informações. Essas plataformas apresentam bons espaços de interatividade entre as partes litigantes e um conciliador, mediador ou árbitro.

Ainda é necessário salientar que, embora nessas plataformas exista algum terceiro humano para realizar a facilitação da negociação, a mediação ou a decisão, já se discute a possibilidade dessas plataformas serem totalmente automatizadas com o uso de IA. A preocupação quanto a isso, porém, diz respeito à justiça das decisões que possam ser proferidas pela utilização de algoritmos, principalmente pelo fato de que estes necessitam passar por um treinamento com dados — os quais podem estar eivados de informações discriminatórias - além de serem complexos demais para permitirem um contraditório propriamente dito - o que vem sendo chamado de opacidade algorítmica. Significa dizer que, não há como negar o medo da programação com certo viés, ou da utilização dos dados que os mesmos usam serem tendenciosos, bem como os efeitos que essas decisões podem 
causar no sistema jurídico e os consequente impactos que podem resultar na vida humana, de forma que grupos minoritários possam continuar sendo oprimidos, havendo assim uma potencialização das discriminações pela tecnologia e a falta da uma individualização de decisão - e de forma prejudicial à possibilidade de recurso contra tais decisões. Por esse motivo, se fala que o uso das plataformas de ODR devem ser utilizados de modo que sempre venham a respeitar os princípios jurídicos fundamentais, pois atualmente as decisões por algoritmos não apresentam ser seguras.

Aliás, muitos tribunais ao redor do mundo começaram a utilizar tecnologias para melhorar a prestação judiciária ao cidadão. Um exemplo da iniciativa pública foi o da Comissão Europeia, que criou uma plataforma para resolver os conflitos com uma forma de fácil acesso e comunicação, pelo fato da plataforma possuir todos os idiomas dos países pertencentes ao bloco europeu. Significa dizer que essas plataformas podem apresentar oportunidades para melhorar o acesso à justiça. No entanto, o uso da ODR deve ser analisado sempre com relação à desigualdade social e as diferenças de realidades de, por exemplo, um país do Norte para um país do Sul global.

No caso do brasileiro já houve experiências com o uso da tecnologia para realização de audiências, como por exemplo, a utilização de videoconferências para oitava de partes e testemunhas. A situação da pandemia fez com que os Tribunais necessitassem se adequar para que as atividades judiciárias não parassem totalmente, abrindo, mais uma vez, espaço para a utilização de meios tecnológicos. Também é de extrema importância salientar que a utilização de ferramentas digitais na solução de conflitos pode contribuir com o direito fundamental do acesso à justiça. No entanto, alguns impasses também podem ser percebidos, principalmente no que tange à realidade da grande desigualdade presente no Brasil. Muitos brasileiros não têm acesso às condições materiais básicas de dignidade — quanto mais, à tecnologia -, e isso complexifica ainda mais a questão da popularização do uso de ODR. Ademais, idosos e pessoas com deficiência devem ser considerados com bastante atenção nesse ínterim, pois suas especificidades têm de ser respeitadas para que tenham igualdade de acesso à tecnologia. Sob essa ótica, a tecnologia, que deveria fornecer um melhor acesso à justiça, pode acabar potencializando as desigualdades e não garantir o referido direito fundamental. Para evitar esse grande problema, o Poder Público deveria promover as condições necessárias, reduzindo desigualdade e oferecendo melhor estrutura para a 
população para dar efetiva acessibilidade digital para aqueles que ainda não a tem, e educação digital aos que demonstram dificuldade para entender e utilizar os meios tecnológicos. Vídeos ou áudios com legendas auxiliam pessoas com deficiência auditiva, por exemplo. Criar as melhores formas para ajudar na acessibilidade das plataformas também é acesso à justiça, essa que tem um conceito extremamente amplo. Por isso, se percebe que ninguém deve ser excluído quando se pensa em meios para solucionar conflitos e promoção de um direito fundamental do cidadão.

\section{REFERÊNCIAS}

ABEDI, Fahimeh; ZELEZNIKOW, John; BELLUCCI, Emilia. Universal standards for the concept of trust in online dispute resolution systems in e-commerce disputes. International Journal of Law and Information Technology, v. 27, n. 3, p. 209-237, 2019. DOI: https://doi.org/10.1093/ijlit/eaz005.

AMORIM, Fernando Sérgio Tenório de. A resolução online de litígios (ODR) de baixa intensidade: perspectivas para a ordem jurídica brasileira. Pensar-Revista de Ciências Jurídicas, v. 22, n. 2, p. 514-539, 2017. DOI: https://doi.org/10.5020/23172150.2017.5397..

ANDERSON, Dorcas Quek. Ethical concerns in court-connected online dispute resolution. International Journal of Online Dispute Resolution, v. 5, n. 1-2, p. 20, 2019. DOI: https://doi.org/10.5553/IJODR/235250022018005102004.

BECKER, Daniel; FEIGELSON, Bruno. Acesso à justiça para além de Cappelletti e Garth: a resoluçÃo de disputas na era digital e o papel dos métodos online de resolução de conflitos (ODR) na mitigação da crise de justiça no Brasil In: LUCON, Paulo Henrique dos Santos et al. (coord.). Direito, Processo e Tecnologia. São Paulo: Thomson Reuters Brasil, 2020. p. 205-220.

BRASIL. Constituição da República Federativa do Brasil de 1988. Disponível em: http://www.planalto.gov.br/ccivil_03/constituicao/constituicao.htm. Acesso em: 28 set 2020 .

BRASIL. Lei 13.105, de 16 de março de 2015. Código de processo civil. Disponível em: http://www.planalto.gov.br/ccivil_03/_Ato2015-2018/2015/Lei/L13105.htm. Acesso em: 28 set 2020 . 
BRASIL. Lei 13.140, de 26 de junho de 2015. Dispõe sobre a mediação entre particulares como meio de solução de controvérsias e sobre autocomposição de conflitos no âmbito da administração pública. Disponível em: http://www.planalto.gov.br/ccivil_03/_ato2015-2018/2015/Lei/L13140.htm. Acesso em: 28 set 2020 .

BRASIL. Lei 13.994, de 24 de abril de 2020. Altera a Lei $\mathrm{n}^{\circ} 9.099$, de 26 de setembro de 1995, para possibilitar a conciliação não presencial no âmbito dos Juizados Especiais Cíveis. Disponível em: http://www.planalto.gov.br/ccivil_03/_Ato20192022/2020/Lei/L13994.htm. Acesso em: 28 set 2020.

CALLIESS, Gralf-Peter; HEETKAMP, Simon Johannes. Online Dispute Resolution: Conceptual and Regulatory Framework. TLI Think, 2019. DOI: http://dx.doi.org/10.2139/ssrn.3505635.

EBNER, Noam; GREENBERG, Elayne E. Strengthening Online Dispute Resolution Justice. Washington University Journal of Law \& Policy, v. 63, n. 1, p. 065-118, 2020. Disponível em: https://openscholarship.wustl.edu/law_journal_law_policy/vol63/iss1/9/. Acesso em 28 set 2020 .

FUJITA, Maíra de Oliveira Lima Ruiz; ALMEIDA, Bianca Santos Cavalli. Meios de solução digital de conflitos-Online Dispute Resolution (ODR). Revista de Processo, Jurisdição e Efetividade da Justiça, v. 5, n. 2, p. 19-35, 2019. Disponível em: https://indexlaw.org/index.php/revistaprocessojurisdicao/article/view/5896. Acesso em: 28 set 2020 .

GAJARDONI, Fernando da Fonseca. Levando o dever de estimular a auto-imposição a sério: uma proposta de releitura do princípio do acesso à justiça à luz do CPC/15. Revista Eletrônica de Direito Processual, v. 21, n. 2, p. 99-114, 2020. DOI: https://doi.org/10.12957/redp.2020.50802.

GONZÁLEZ, Wendolyne Nava. Los mecanismos extrajudiciales de resolución de conflictos en línea: su problemática en el derecho internacional privado. ACDI-Anuario Colombiano de Derecho Internacional, n. 13, p. 5, 2020. DOI: http://dx.doi.org/10.12804/revistas.urosario.edu.co/acdi/a. 7524. 
HASSAN, Kamal Halili et al. The use of technology in the transformation of business dispute resolution. European journal of law and economics, v. 42, n. 2, p. 369-381, 2016. DOI: https://doi.org/10.1007/s10657-012-9375-7.

KAPLAN, Andreas; HAENLEIN, Michael. Rulers of the world, unite! The challenges and opportunities of artificial intelligence. Business Horizons, v. 63, n. 1, p. 37-50, 2020. DOI: https://doi.org/10.1016/j.bushor.2019.09.003.

LARSON, David Allen. ODR Accessibility for Persons with Disabilities: We Must Do Better. Online Dispute Resolution: Theory and Practice (2nd ed. Eleven International $\begin{array}{llll}\text { Publishers, } & \text { Forthcoming } & \text { Fall 2020), }\end{array}$ DOI:http://dx.doi.org/10.2139/ssrn.3614838.

LIMA, Gabriela Vasconcelos; FEITOSA, Gustavo Raposo Pereira. Online dispute resolution (ODR): a solução de conflitos e as novas tecnologias. Revista do Direito, v. 3, n. 50, p. 53-70, 2016. DOI: http://dx.doi.org/10.17058/rdunisc.v3i50.8360.

MANIA, Karolina. Online dispute resolution: The future of justice. International Comparative Jurisprudence, v. 1, n. 1, p. 76-86, 2015. DOI: https://doi.org/10.1016/j.icj.2015.10.006.

MORALES, Emiliano Carretero. La utilidade de los ODR en los casos de violencia de género. Revista Eletrônica de Direito Processual, v. 18, n. 1, 2017. DOI: https://doi.org/10.12957/redp.2017.28490.

NASCIMENTO JUNIOR, Vanderlei Freitas. A evolução dos métodos alternativos de resolução de conflitos em ambiente virtual: on line dispute resolution. Revista Eletrônica da Faculdade de Direito de Franca, v. 12, n. 1, p. 265-282, 2017. DOI: https://doi.org/10.21207/1983.4225.439.

NETTO, José Laurindo de Souza; FOGAÇA, Anderson Ricardo; GARCEL, Adriane. Métodos autocompositivos e as novas tecnologias em tempos de COVID-19: online dispute resolution - ODR. Relações Internacionais no Mundo Atual, v. 1, n. 26, p. 21-32, 2020. DOI: http://dx.doi.org/10.21902/Revrima.v2i27.3989.

NOLAN-HALEY, Jacqueline. International Dispute Resolution and Access to Justice: Comparative Law Perspectives. Journal of Dispute Resolution, p. 391, 2020. Disponível em: 
https://scholarship.law.missouri.edu/cgi/viewcontent.cgi?article=1869\&context=jdr. Acesso em: 28 set 2020.

OSNA, Gustavo. Acceso a la justicia, cultura y online dispute resolution. Derecho PUCP, n. 83, p. 9-27, 2019. DOI: http://dx.doi.org/10.18800/derechopucp.201902.001.

PAOLINELLI, Camilla Mattos; CASPAR, Rafael Chiari. Reflexões sobre Direito, tecnologia e a utilização de ferramentas de Online Dispute Resolution em demandas trabalhistas In: ALVES, Isabella Fonseca (org.). Inteligência Artificial e Processo. Belo Horizonte: D’Plácido, 2020. p. 177-204.

PARO, Giácomo; MARQUES, Ricardo Dalmaso; DUARTE, Ricardo Quass. On-Line Dispute Resolution (ODR) e o interesse processual In: LUCON, Paulo Henrique dos Santos et al. (coord.). Direito, Processo e Tecnologia. São Paulo: Thomson Reuters Brasil, 2020. p. 277-326.

PATIL, Ashok R. Role of Law Schools in Justice Delivery System through Online Mediation In: SANTANO, Ana Claudia; GABARDO, Emerson; NAGARATHNA, Annappa (org.). Direitos Fundamentais, Tecnologia e Educação. Curitiba: Íthala, 2019. p. 163-170. Disponível em: https://www.researchgate.net/profile/Sakshi_Goyal14/publication/342521131_Direit os_fundamentais_tecnologia_e_educacao_India/links/5ef97f1ca6fdcc4ca43a1f7c/Dir eitos-fundamentais-tecnologia-e-educacao-India.pdf\#page=164. Acesso em: 28 set 2020 .

PEREIRA, Luiz Fernando Casagrande; SCHINEMANN, Caio César Bueno. On-line Dispute Resolution no processo civil brasileiro: o caso das plataformas de indenização contra companhias aéreas In: LUCON, Paulo Henrique dos Santos et al. (coord.). Direito, Processo e Tecnologia. São Paulo: Thomson Reuters Brasil, 2020. p. 439460.

RULE, Colin. Online Dispute Resolution and the Future of Justice. Annual Review of Law and Social Science, v. 16, 2020. DOI: https://doi.org/10.1146/annurev-lawsocsci101518-043049.

SCHMIDT-KESSEN, Maria José; NOGUEIRA, Rafaela; GAMITO, M. Cantero. Success or Failure?-Effectiveness of Consumer ODR Platforms in Brazil and in the EU. 
Journal of Consumer Policy, p. 1-28, 2020. DOI: https://doi.org/10.1007/s10603020-09448-y.

SHOPE, Mark. The International Arbitral Institution Response to COVID-19 and Opportunities for Online Dispute Resolution. Contemporary Asia Arbitration Journal, 2020.2 Disponível em: https://papers.ssrn.com/sol3/papers.cfm?abstract_id=3616612. Acesso em: 28 set 2020 .

SILVA, Sabrina Jiukoski da; SILVA, Rafael Peteffi da; SANTOS, Ricardo Soares Stersi dos. A mediação e a conciliação como instrumentos de acesso à justiça e a sua perspectiva a partir do Código de Processo Civil: o contraponto entre a cultura da sentença e a cultura do consenso. Revista Eletrônica de Direito Processual, v. 21, n. 1, p. 392-415, 2020. DOI: https://doi.org/10.12957/redp.2020.44635.

TAN, Vivi. Online dispute resolution for small civil claims in Victoria: A new paradigm in civil justice. Deakin Law Review, v. 24, p. 101, 2019. Disponível em: https://papers.ssrn.com/sol3/papers.cfm?abstract_id=3452952. Acesso em: 28 set 2020.

VASCONCELOS, Ronaldo; CARNAÚBA, César Augusto Martins. Custos de transação do processo e Online Dispute Resolution: um sistema multipartas 4.0 economicamente eficiente

In: LUCON, Paulo Henrique dos Santos et al. (coord.). Direito, Processo e Tecnologia. São Paulo: Thomson Reuters Brasil, 2020. p. 613-630.

ZANFERDINI, Flávia Almeidai Montingelli; OLIVEIRA, Rafael Tomaz. Online Dispute Resolution in Brazil: are we ready for this cultural turn? Revista Paradigma, v. 24, n. 1 , 2015 . Disponível em: http://revistas.unaerp.br/index.php/paradigma/article/view/589. Acesso em: 28 set 2020 .

ZELEZNIKOW, John. Can artificial intelligence and online dispute resolution enhance efficiency and effectiveness in courts. In: International Journal for Court Administration, v. 8, n. 2, p. 30-45, 2016. DOI: http://doi.org/10.18352/ijca.223. 